\title{
Prevention of thrombotic disorders by antithrombotic diet and exercise: evidence by using global thrombosis tests
}

\author{
Junichiro Yamamoto*,1, Yoshinobu ljiri $^{2}$, Hideo Ikarugi ${ }^{3}$, Kazunori Otsui ${ }^{4}$, Nobutaka Inoue ${ }^{5}$ \\ \& Kjell S Sakariassen ${ }^{6}$ \\ ${ }^{1}$ Kobe Gakuin University, Kobe 651-2180, Japan \\ ${ }^{2}$ Faculty of Health \& Nutrition, Osaka Shoin Women's University, Osaka 577-8550, Japan \\ ${ }^{3}$ School of Economics, University of Hyogo, Kobe 651-2197, Japan \\ ${ }^{4}$ Clinical Department of General Internal Medicine, Kobe University Hospital, Kobe 650-0017, Japan \\ ${ }^{5}$ Department of Cardiovascular Medicine, Kobe Rosai Hospital, Kobe 651-0053, Japan \\ ${ }^{6}$ KellSa s.a.s. Str. Campo e Zampo 12, I-13900 Biella, BI, Italy \\ * Author for correspondence: Tel./Fax: +81 78936 6046; yamamoto@nutr.kobegakuin.ac.jp
}

Prevention of thrombotic disorders has priority over treatment. There are only two pathologically relevant tests which are suitable for measuring the overall thrombotic status both in experimental conditions and in humans. The Global Thrombosis Test (GTT) and the Global Parallel-Plate Thrombosis Test can detect the pathologically relevant global thrombotic status. These tests have been successfully used for monitoring the effect of antithrombotic drugs and for developing novel antithrombotic agents. By using GTT, varieties of fruits, vegetables, and regular physical exercise have been tested for the effect on global thrombotic status. This review discusses the published evidence for the benefit of diet of selected fruit and vegetable varieties and doing regular physical exercise on improving thrombotic status. Future clinical trials monitored by GTT or Global Parallel-Plate Thrombosis Test could decide on the effectiveness of an experimentally proven antithrombotic diet with regular physical exercise in the prevention of thrombotic diseases.

Lay abstract: Prevention of deadly diseases like heart attack or stroke is more effective than treating patients with already progressed disease. Epidemiologic studies raised the possibility that eating healthy food and doing physical exercise may prevent thrombotic diseases. To create an 'antithrombotic diet', fruits and vegetables should be selected and the benefit of diet and exercise should be monitored in people. We found that the Global Thrombosis Tests are useful for both selection of antithrombotic diet components and monitoring thrombotic status of individuals.

First draft submitted: 18 September 2017; Accepted for publication: 2 January 2018; Published online: 24 January 2018

Keywords: antithrombotic vegetables $\bullet$ cardiovascular disease $\bullet$ exercise paradox $\bullet$ fibrinolysis $\bullet$ global parallel-plate thrombosis test $\bullet$ global thrombosis test $\bullet$ platelet aggregation $\bullet$ shear rate $\bullet$ shear stress $\bullet$ stroke

\section{Arterial thrombosis/thrombolysis in vivo tests in experimental animals}

Techniques using laser irradiation to induce vascular injury and subsequent platelet-rich thrombus formation were established in the early 1970s [1-10]. Helium-Neon (He-Ne) laser-induced thrombosis in vivo model, which selectively damaged the vascular endothelium has been used extensively in thrombosis research [11-16]. Yamamoto et al. found a good correlation between a shear-induced ex vivo global thrombosis test and the 'gold standard' He- $\mathrm{Ne}$ laser-induced thrombosis in vivo test [17]. The He-Ne laser-induced in vivo thrombosis test allowed the assessment not just the formation and growth of thrombus but also its fragmentation, embolism and lysis [18-23]. Irradiating the carotid artery of a mouse with He-Ne laser, real-time measurement of thrombus size and its changes over time is shown in Figure 1. 
(A)

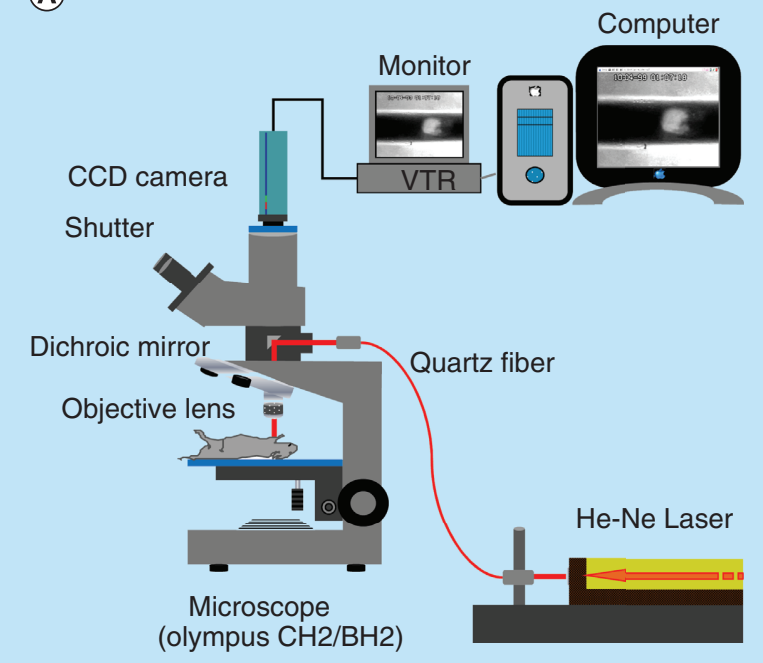

(C)

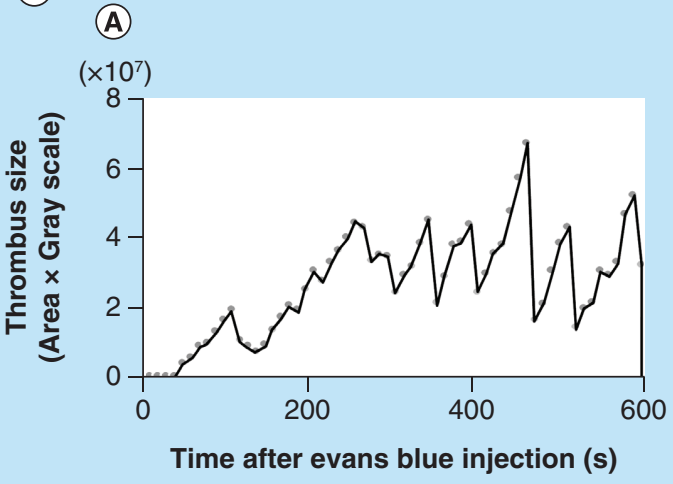

(olympus $\mathrm{CH} 2 / \mathrm{BH} 2$ )

Quartz fiber

Time after evans blue injection (s)
(B)
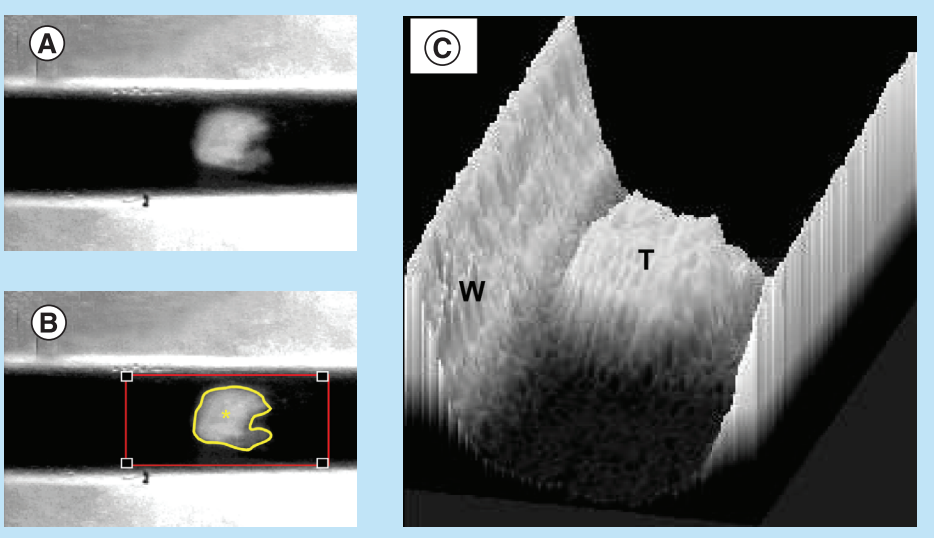

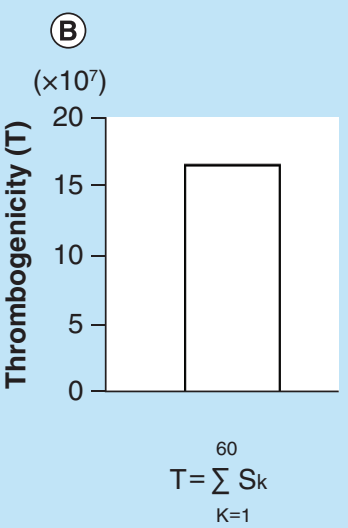

Figure 1. Measurement of thrombotic status in rodents (in vivo). He-Ne laser-induced thrombosis system (A). Measurement of thrombus size in mouse carotid artery (B). Thrombus formed in carotid artery (A); thrombus delineated by software (B); thrombus formed by software (C). Change in thrombus size over $600 \mathrm{~s}$ and calculation of the index of thrombotic status (C). Consecutive thrombus size over time (A); an index of thrombogenicity (B).

He-Ne: Helium-Neon; T: Thrombus formed by software; W: Vessel wall.

\section{Technical details of He-Ne laser thrombosis model}

Evans blue was injected into a rat anesthetized with sodium pentobarbital. An intestinal loop was spread out flat on a self-constructed object stage, which was mounted on the adjustable plate of an Olympus microscope. An O-ring was placed on the mesentery to stop the movement of the vessel. Selected mesenteric arterioles and venules were irradiated with a focused $\mathrm{He}-\mathrm{Ne}$ laser beam of $15 \mu \mathrm{m}$ diameter. A single $5 \mathrm{~s}$ irradiation was repeated every $30 \mathrm{~s}$ until an occlusive thrombus was formed. The number of laser irradiations is necessary to induce fully occlusive thrombus formation was counted. The antithrombotic effect was assessed by the increase of the number of irradiations necessary to occlusion [11]. Similarly, thrombus was formed in the carotid artery of mice [12]. An indwelling catheter was inserted into the left femoral artery and the left carotid artery was exposed. Having transferred the mouse onto a microscope stage, laser beam $(200 \mu \mathrm{m}$ in diameter at the focal plane) was targeted onto the center of the exposed carotid artery. Thrombus formation was monitored under fiberoptic epi-illumination through a microscope with an attached CCD camera and recorded with a video recorder. An image of the thrombus was taken every $10 \mathrm{~s}$ over $600 \mathrm{~s}$ and the thrombus size was analyzed by Analyst software. In brief, the lumen of the laser-targeted vessel was fitted into an optical frame, the grayscale threshold level was set to delineate the thrombus, and the thrombus area was measured. The thrombus size was calculated by multiplication of the area and grayscale values. During 


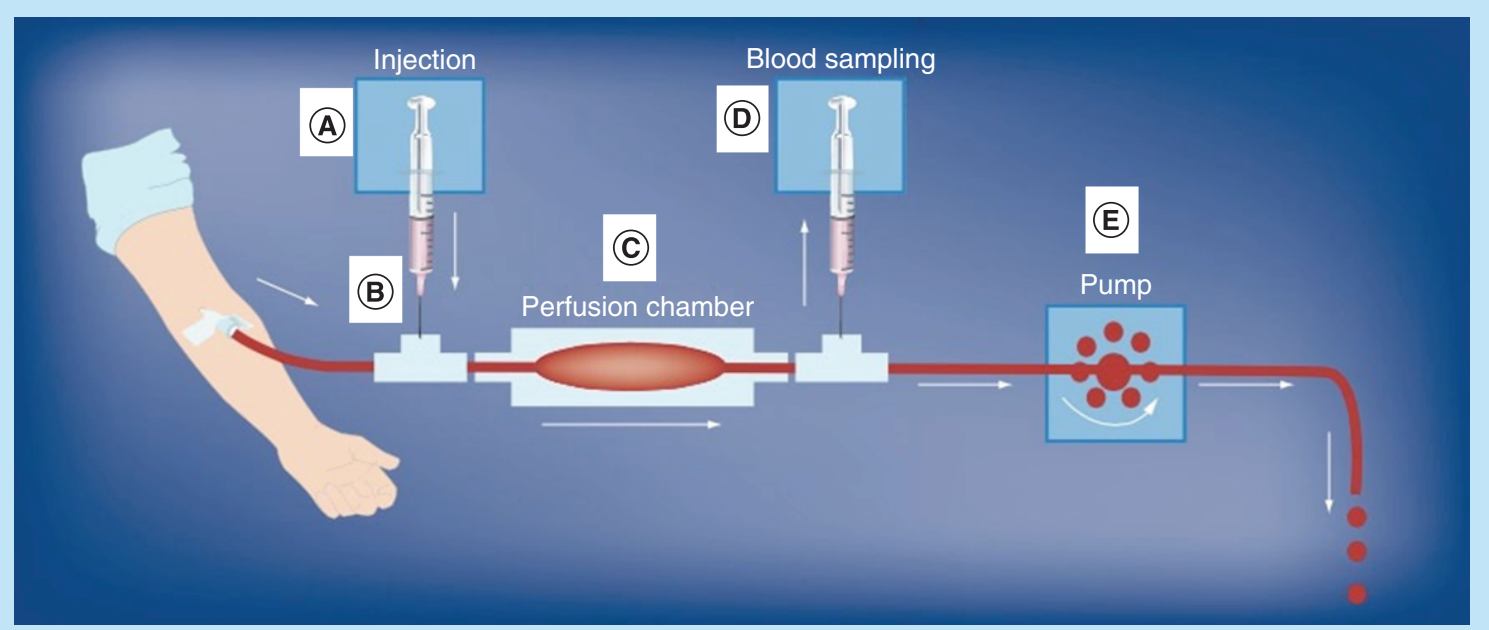

Figure 2. The global parallel-plate blood perfusion chambers test. The various components of the blood perfusions system are as follows. (A) pump for injection of test agents; (B) mixing chamber device for test agents in the flowing blood stream; (C) parallel-plate perfusion chamber with thrombogenic surface; (D) pump for drawing of postchamber blood samples for bioanalysis; (E) pump drawing blood from vein through perfusion chamber.

Reproduced with permission from [37].

the irradiations, the size of thrombus mass changed due to growth and embolization, but complete occlusion did not occur. A total sum of 60 individual images taken over $600 \mathrm{~s}$ were analyzed to calculate the index of thrombogenicity [13].

\section{Platelet-rich thrombus formation ex vivo in native blood under flow conditions}

Plasma fibrinolytic activity can be assessed in vitro or in vivo, by measuring various biomarkers. Measurement of thrombolysis under flow revealed the important contribution of platelets not just to the formation but also to lysis of a thrombus [24-32].

\section{Arterial \& venous thrombus formation triggered by arterial subendothelium, collagen or tissue factor/phospholipids in perfusion chambers under normal \& atherosclerotic native blood flow conditions}

New frontier research was developed by HR Baumgartner and colleagues and by KS Sakariassen and colleagues by the developments and validations of thrombus formation triggered by thrombotic surfaces in annular and parallel-plate blood perfusion chambers [33-35].

Important features of this technique were the use of native blood (nonanticoagulated blood) at venous, arterial and atherosclerotic blood flow conditions. The blood was drawn from an antecubital vein through a 19-gauge syringe at $10 \mathrm{ml} / \mathrm{min}$ by a peristaltic roller pump placed distal to the perfusion chamber as shown in Figure 2 . The respective blood wall shear rates in the parallel-plate perfusion chambers were $100 \mathrm{~s}^{-1}$ (venous blood flow), $650 \mathrm{~s}^{-1}$ (averaged-sized arteries), $2600 \mathrm{~s}^{-1}$ (moderate arterial stenosis - stenosis occlusion of 60\%), 10,500 s-1 (severe arterial stenosis - stenosis occlusion of $80 \%$ ) and $32,000 \mathrm{~s}^{-1}$ (very severe stenosis occlusion - stenosis occlusion of $89 \%$ ). The thrombogenic surfaces of the perfusion chambers consist of either human vascular subendothelium, collagen or tissue factor/phospholipids. Parameters of thrombus formation measured by morphology are platelet surface adhesion, size of thrombi and fibrin deposition. Complementary methods to measure fibrin and platelet deposition by immunological methods were developed as well. Biomarkers of platelet activation, coagulation and fibrinolysis can be measured from blood samples collected downstream to the site of thrombus formation during the blood perfusion period. A corresponding miniature parallel-plate perfusion chamber was also developed where thrombus formation is studied simultaneously at three different shear conditions at a blood flow rate of $1 \mathrm{ml} / \mathrm{min}$ [36]. 
(A)

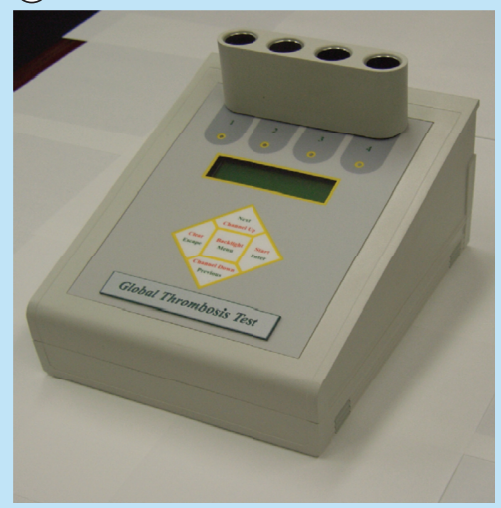

(B)

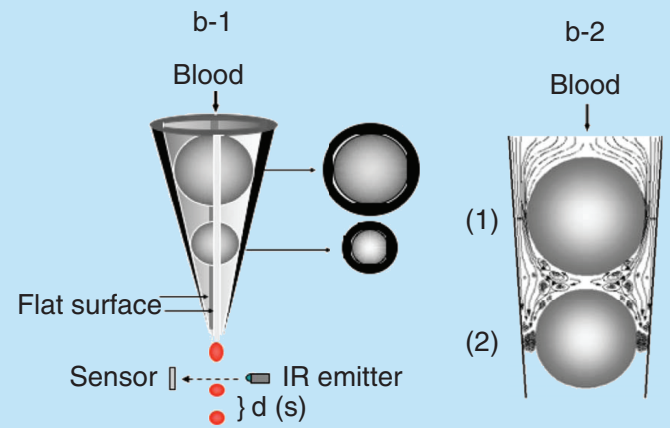

(C)

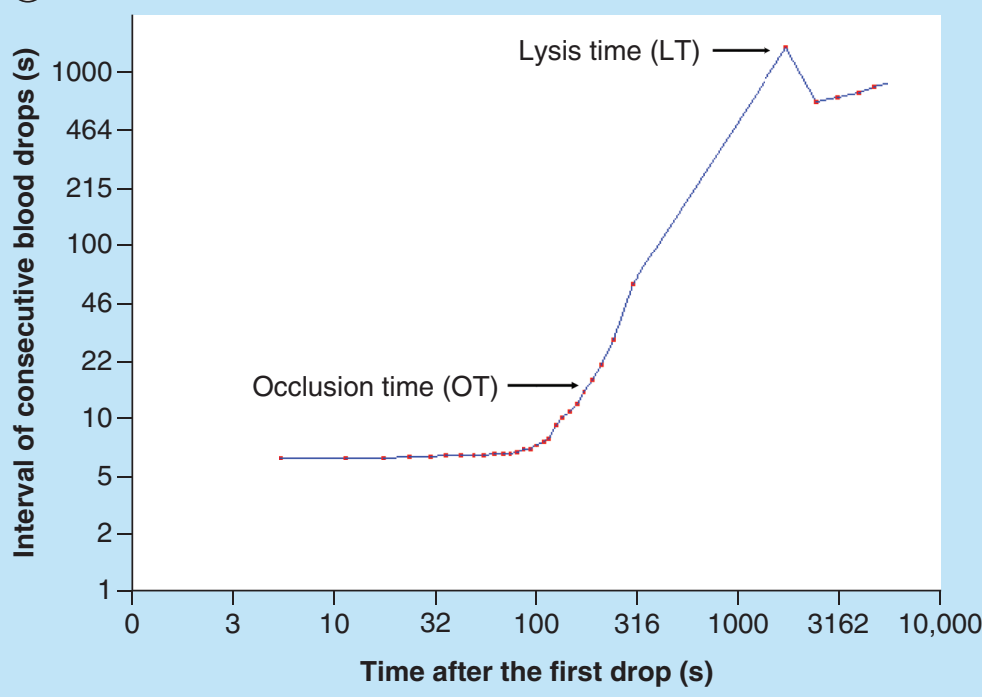

Figure 3. GTTmeasurement using native blood. GTT instrument (A) and principle of the measurement (B). Platelets in native blood are activated by high shear forces in the upper gaps (1). Fibrin stabilized thrombi formed between the two bearing balls occlude the lower gaps (2). Real time recording of GTT measurement (C).

IR: Infra red; GTT: Global thrombosis test; LT: Lysis time, time from the start of measurement until the first blood drop detected after OT + $200 \mathrm{~s}$ stabilization; ОT: Time between two consecutive blood drops exceeding the default (15 s).

The parallel-plate perfusion chambers have been validated with a large number of studies including patients with bleeding disorders and patients on antithrombotic agents, both platelet inhibitors and coagulation inhibitors [38,39]. Also, combination therapies with platelet inhibitors and coagulation inhibitors were included.

\section{Arterial thrombosis test (POC) performed from native blood under pathologically relevant flow conditions}

Unique features of the point-of-care (POC) instrument developed by Kovacs et al., are the testing native blood and initiating thrombus formation solely by pathologically relevant high shear stress [40-45]. The POC shear-induced test drives the tested native blood to flow through narrow gaps and thrombi formed in the poststenotic area are captured in a distal second gap, thus arresting the flow in the system. The technique measures the time of occlusive thrombus formation and the subsequent endogenous lysis of the occlusion. The principle of Global Thrombosis Test (GTT) is shown in Figure 3.

The measurement starts by withdrawal of blood sample from the antecubital vein using a $21 \mathrm{G}$ needle with a butterfly cannula. To minimize platelet activation during blood sampling, the double syringe technique was used in each subject. The first $3 \mathrm{ml}$ blood was used for routine blood tests, and the subsequent $4.0 \mathrm{ml}$ was used for 


\begin{tabular}{|c|c|c|c|}
\hline \multirow[t]{2}{*}{ Country } & Vegetables & Fruits & \multirow[t]{2}{*}{ Ref. } \\
\hline & Target for daily intake of vegetables & Target for daily intake of fruits & \\
\hline Japan & $350 \mathrm{~g}$ & More than $100 \mathrm{~g}$ & [65] \\
\hline NL & At least $200 \mathrm{~g}$ & At least $200 \mathrm{~g}$ & [59] \\
\hline UK & \multicolumn{2}{|l|}{ At least five portions $(400 \mathrm{~g}$ ) of a variety of fruit and vegetables } & [60] \\
\hline USA & 2.5 cup (approximately $600 \mathrm{~g}$ ) for 2000 -calorie level pattern & $\begin{array}{l}\text { Two cups (approximately } 480 \mathrm{~g} \text { ) for } 2000 \text {-calorie level } \\
\text { pattern }\end{array}$ & [61] \\
\hline \multicolumn{4}{|c|}{ Physical exercise } \\
\hline Japan & \multicolumn{2}{|c|}{$\begin{array}{l}\text { Adults (aged } 20-64 \text { years): male } 9000 \text { steps, female } 8500 \text { steps per day; Older adults ( } 65 \text { years and older): male } 7000 \text { steps, } \\
\text { female } 6000 \text { steps per day }\end{array}$} & [66] \\
\hline $\mathrm{NL}$ & \multicolumn{2}{|c|}{$\begin{array}{l}\text { Adults (aged } 18-54 \text { years): at least } 30 \mathrm{~min} \text { of moderate- to vigorous-intensity physical activity with moderate defined as } \\
4.0-6.4 \mathrm{METs} \text { and vigorous defined as } \geq 6.5 \mathrm{METs} \text { on a minimum of } 5 \text { days per week. Older adults ( } 55 \text { years and older): at } \\
\text { least } 30 \mathrm{~min} \text { of moderate defined as } 3.0-4.9 \mathrm{METs} \text { and vigorous defined as } \geq 5.0 \mathrm{METs} \text { on a minimum of } 5 \text { days per week. } \\
\text { For inactive people: any additional amount of any type of exercise is considered useful, regardless of intensity, duration } \\
\text { and frequency }\end{array}$} & [62] \\
\hline UK & \multicolumn{2}{|c|}{$\begin{array}{l}\text { Adults (aged 19-64 years): at least } 150 \text { min of moderate-intensity aerobic activity a week plus muscle strengthening } \\
\text { activities on two days or more of the week; or } 75 \text { min of vigorous intensity aerobic activity plus muscle strengthening } \\
\text { activities on } 2 \text { days or more of the week; or a combination of moderate and vigorous aerobic activity every week. Older } \\
\text { adults ( } 65 \text { years and older): at least } 2 \text { days a week, try to take part in types of activities such as cycling, Tai chi, yoga or } \\
\text { stretching exercises. And remember, it is never too late to turn over a new leaf and become more active - just go easy to } \\
\text { start with and build up your fitness gradually. If } 30 \text { min all in one go sounds a bit too much to start with, do not worry - } \\
\text { you can make up the daily } 30 \text { min by adding together shorter bouts of activity, of at least } 10 \text { min each }\end{array}$} & [63] \\
\hline US & \multicolumn{2}{|c|}{$\begin{array}{l}\text { Adults (aged 18-64 years): at least } 150 \mathrm{~min} \text { a week of moderate-intensity, or } 75 \mathrm{~min} \text { a week of vigorous-intensity aerobic } \\
\text { physical activity, or an equivalent combination of moderate-and vigorous-intensity aerobic activity. Aerobic activity should } \\
\text { be performed in episodes of at least } 10 \mathrm{~min} \text {, and preferably, it should be spread throughout the week. Adults should also } \\
\text { include muscle-strengthening activities that involve all major muscle groups on } 2 \text { or more days a week. Older adults } \\
\text { ( } 65 \text { years and older): when older adults cannot meet the adult guidelines, they should be physically active as their abilities } \\
\text { and conditions will allow. Older adults should do exercises that maintain or improve balance if they are at risk of falling }\end{array}$} & [64] \\
\hline
\end{tabular}

GTT measurement $[44,45]$. Syringe with the blood sample was inserted into the disposable GTT test tube and the measurements started within $15 \mathrm{~s}$ from withdrawing the blood. During the measurement blood flows under gravity through small gaps, in which platelets are activated by the initial high shear rate $\left(12,000-14,000 \mathrm{~s}^{-1}\right)$. Formation of fibrin-stabilized thrombus and its lysis are detected.

\section{High shear-induced ex vivo thrombosis/fibrinolysis test of native blood sample: comparison with conventional tests}

GTT proved to be sensitive in detecting small differences in thrombotic and fibrinolytic activities between age, gender, smoker or nonsmoker people [46-48], in metabolic syndrome [49] and in stroke patients [50]. In these studies, GTT surpassed the sensitivity of routine coagulation tests like the prothrombin time test and activated partial thromboplastin time test especially in monitoring oral anticoagulants [51]. GTT detected hyper thrombotic status after overwork, which could not be detected by conventional coagulation tests [52].

The benefit of using GTT in various clinical conditions (myocardial infarction, atrial fibrillation, monitoring dual antiplatelet or oral thrombin inhibitor medications after coronary angioplasty), has been documented in several trials involving large number of patients [53-58].

Reproducibility of GTT has been tested and published. If blood sampling is performed by a trained operator, the reproducibility of both thrombotic (OT) and thrombolytic activity (LT) is good (the intra-assay CV was OT $=10 \%$ and for LT $=6 \%$ and the inter-assay CV was OT $=8 \%$ and for LT $=9 \%$ ) and allows credible statistical analysis of the findings [55].

\section{Prevention of thrombotic disorders by long-term antithrombotic diet of fruits \& vegetables \& doing physical exercise}

It is widely believed that intake of fruits, vegetables and physical exercise is beneficial to thrombotic status especially in those who are at risk of thrombotic diseases. In many countries recommendation for an antithrombotic diet and adequate physical exercise has been proposed to the relevant health authorities (Table 1) [59-66]. 
Effect of fruits \& vegetables on thrombotic status

Quality and quantity of daily intake of fruits and vegetables shows great differences in various countries. Large epidemiological study in the USA found that the risk of coronary heart disease in adults depends on the consumption of healthful and unhealthful plants [67]. In this study fruits, vegetables and other processed diets were classified as 'healthy' (raisins, grapes, prunes, bananas, cantaloupe, watermelon, fresh apples or pears, oranges, grapefruit, strawberries, blueberries, peaches or apricots or plums, tomatoes, tomato juice, tomato sauce, broccoli, cabbage, cauliflower, Brussels sprouts, carrots, mixed vegetables, yellow or winter squash, eggplant or zucchini, yams or sweet potatoes, spinach cooked, spinach raw, kale or mustard orchard greens, iceberg or head lettuce, romaine or leaf lettuce, celery, mushrooms, beets, alfalfa sprouts, garlic, corn, nuts, peanut butter, string beans, tofu or soybeans, beans or lentils, peas or lima beans, vegetable oil used for cooking, tea, coffee, decaffeinated coffee) and 'less healthy' (apple cider or juice, orange, grapefruit and other fruit juice, white rice, baked or mashed potatoes, potato or corn chips etc).

By testing native blood using the shear-induced GTT, Yamamoto et al. found that antithrombotic activity of fruits and vegetables classified as 'healthy' is still depend on the tested varieties. Accordingly, varieties of the same fruit or vegetable can be antithrombotic, prothrombotic or without effect on thrombotic status [68-74]. The antithrombotic varieties demonstrated in animal experiments were effective in short and long-term intake by humans [75,76]. Thus, selection of varieties of fruits and vegetables for antithrombotic effect by GTT is a promising approach to developing antithrombotic diet for the prevention of thrombotic disorders such as cardiovascular disease and stroke. Large scale studies and trials are needed to verify this claim.

\section{Physical exercise \& exercise paradox}

Epidemiological and clinical studies suggested that regular exercise is an efficient way to prevent arterial thrombotic diseases [77-81]. The recommended 'government guidelines' is shown in Table 1. Despite such recommendation, the benefit of exercise is still not generally accepted, debated and objections are referred as 'exercise paradox' or 'double-edged sword in exercise' [82-86]. Ikarugi and Yamamoto proposed that regular assessment of thrombotic status using GTT may be helpful in individualizing the effect of exercise in people at risk [87].

\section{Limitations of tests using native blood}

The requirement of starting the tests within 15-20 s after withdrawal of blood samples mandates experienced operator or phlebotomist, and organization that the instrument should be near to the tested person. It is the latter which is most difficult to ensure, as in the present clinical practice blood samples are taken, stored and tested later in different laboratories.

\section{Conclusion \& future perspective}

The concept of preventing arterial thrombotic disorders by long-term intake of an experimentally proven antithrombotic diet and monitored regular physical exercise is challenging and intriguing. The key to success is finding test(s) capable of monitoring thrombotic status under pathologically relevant conditions. In contrast to common platelet function or coagulation tests currently in use, the shear-induced global thrombosis and thrombolysis test and the global parallel-plate thrombosis test performed with native (nonanticoagulated) blood are suitable for screening fruit and vegetable varieties for antithrombotic effect. The use of these tests under experimental conditions can result in establishing an antithrombotic diet. Having found the pathologically relevant tools of testing and monitoring thrombotic status of individuals, future work should be focused on organizing large scale and monitored trials involving healthy people, and those who are at risk of atherothrombotic diseases and cardiovascular events. The outcome of such trials may justify the everyday consumption of an antithrombotic diet with regular physical exercise, and this would be a simple and economical way of prevention of arterial thrombotic diseases.

\section{Author's contributions}

All authors contributed as writers of the text and preparation of the table and figures.

\section{Acknowledgements}

We would like to thank S Watanabe, President of Life Science Promoting Foundation, Tokyo, Japan, and S Biesbroek, Centre for Nutrition, Prevention and Health Services, National Institute for Public Health and the Environment (RIVM), Antonie van Leeuwen- 


\section{Executive summary}

- Interest in prevention of thrombotic disorders by antithrombotic vegetable varieties and physical exercise is increasing. Pathologically relevant point-of-care global tests for the assessment of global thrombotic status are badly needed.

- The Global Thrombosis Test enables the simultaneous measurement of platelet reactivity to high shear stress, platelet procoagulant and endogenous fibrinolytic activity. This technique proved to be suitable for screening fruits and vegetables for antithrombotic effect, making possible to establish an antithrombotic diet and also to individualize the need of physical exercise in people at risk of thrombotic events. The Global Parallel-Plate Thrombosis Test enables also the simultaneous measurements of platelet activation, coagulation and fibrinolytic activities during thrombus formation.

- Global Thrombosis Test-monitored or Global Parallel-Plate Thrombosis Test-monitored large scale trials are needed to verify the beneficial effect of an antithrombotic diet with regular physical exercise in the prevention of arterial thrombotic events.

hoeklaan 9, Bilthoven 3721 MA, The Netherlands, for their help in getting Japanese, European and the US Governmental dietary and physical exercise recommendations.

Financial \& competing interests disclosure

The authors have no relevant affiliations or financial involvement with any organization or entity with a financial interest in or financial conflict with the subject matter or materials discussed in the manuscript. This includes employment, consultancies, honoraria, stock ownership or options, expert testimony, grants or patents received or pending, or royalties.

No writing assistance was utilized in the production of this manuscript.

\section{Open access}

This work is licensed under the Creative Commons Attribution 4.0 License. To view a copy of this license, visit http://creativecomm ons.org/licenses/by/4.0/

\section{References}

Papers of special note have been highlighted as: $\bullet$ of interest; $\bullet \bullet$ of considerable interest

1. Arfors KE, Hint HC, Dhall DP, Matheson NA. Counteraction of platelet activity at sites of laser-induced endothelial trauma. Br. Med. J. 16(4), 430-431 (1968).

2. Kovács IB, Csalay L, Görög P. Laser-induced thrombosis in the microcirculation of the hamster cheek pouch and its inhibition by acetylsalicyclic acid. Microvasc. Res. 6, 194-201 (1973).

3. Kovács IB, Tigyi-Sebes A, Trombitás K et al. Evans blue: an ideal energy-absorbing material to produce intravascular microinjury by HE-NE gas laser. Microvasc. Res. 10, 107-124 (1975).

- Important article describing helium neon (He-Ne) laser-induced thrombosis in experimental animals (in vivo).

4. Kovács IB, Sebes A, Trombitás K et al. Proceedings: improved technique to produce endothelial injury by laser beam without direct damage of blood cells. Thromb. Diath. Haemorrh. 34(1), 331 (1975).

5. Görög P, Kovács IB. Antiarthritic and antithrombotic effects of topically applied dimethyl sulfoxide. Ann. NY Acad. Sci. 243, 91-97 (1975).

6. Görög P, Kovács B. Thrombus formation, hemostasis, adhesiveness of leukocytes and morphological abnormalities in the microcirculation of adjuvant arthritic rats. Agents Actions 6(5), 607-612 (1976).

7. Görög P, Kovács IB. Laser-induced thrombus formation and vascular reactivity in the microcirculation of the spontaneously hypertensive rat. Blood Vessels 14(5), 294-302 (1977).

8. Görög P, Kovács IB. Anti-inflammatory effect of sialic acid. Agents Actions 8(5), 543-545 (1978).

9. Görög P, Kovács IB. Thrombocytosis and platelet aggregates in the circulation of adjuvant arthritic rats. Arthritis Rheum. 21(2), 256-259 (1978).

10. Kovács IB, Görög P. Laser-induced thrombosis test suitable for pharmacological screening studies. Microvasc. Res. 18(3), 403-412 (1979).

- Describes the possible application of a He-Ne laser-induced thrombosis model to develop drugs.

11. Yamamoto J, Iizumi H, Hirota R et al. Effect of physical training on thrombotic tendency in rats: decrease in thrombotic tendency measured by the He-Ne laser-induced thrombus formation method. Haemostasis 19(5), 260-265 (1989).

- Our first publication on He-Ne laser-induced thrombosis in rat mesenteric microvessels. 
12. Sasaki Y, Morii S, Yamashita T et al. Antithrombotic effect of argatroban on the pial vessels of the rat: a study with He-Ne laser-induced thrombus formation. Haemostasis 23(2), 104-111 (1993).

- The first publication of He-Ne laser-induced thrombosis in rat pial microvessels.

13. Ijiri $Y$, Miura M, Hashimoto $M$ et al. A new model to evaluate the diet-induced prothrombotic state, using He-Ne laser-induced thrombogenesis in the carotid artery of apolipoprotein E-deficient and low-density lipoprotein receptor-deficient mice. Blood Coagul. Fibrinolysis 13(6), 497-504 (2002).

- The first publication of He-Ne laser-induced thrombosis model in mouse carotid artery.

14. Falati S, Gross P, Merrill-Skoloff G et al. Real-time in vivo imaging of platelets, tissue factor and fibrin during arterial thrombus formation in the mouse. Nat. Med. 8(10), 1175-1181 (2002).

- Describes the contribution of platelets and fibrin in arterial thrombosis in the mouse using the He-Ne laser-induced thrombosis method and confocal microscopy.

15. Furie B, Furie BC. Mechanisms of thrombus formation. N. Engl. J. Med. 359, 938-949 (2008).

16. Furie B, Furie BC. The molecular basis of platelet and endothelial cell interaction with neutrophils and monocytes: role of P-selectin and the P-selectin ligand, PSGL-1. Thromb. Haemost. 74(1), 224-227 (1995).

17. Yamamoto J, Tamura Y, Ijiri Y et al. Evaluation of antithrombotic effect: importance of testing components and methodologies. Drug Discov. Ther. 9(4), 258-266 (2015).

- Review comparing He-Ne laser-induced thrombosis test (in vivo) and shear-induced thrombosis tests using native blood (ex vivo/in vitro) in experimental animals.

18. Kawano M, Watanabe S, Sasaki Y, Giddings JC, Yamamoto J. Adjuvant effect of argatroban on staphylokinase induced thrombolysis of platelet rich thrombi in rat mesenteric venules in vivo. Thromb. Res. 86(2), 115-126 (1997).

19. Yamamoto J, Kawano M, Hashimoto $\mathrm{M}$ et al. Adjuvant effect of antibodies against von Willebrand Factor, fibrinogen, and fibronectin on staphylokinase-induced thrombolysis as measured using mural thrombi formed in rat mesenteric venules. Thromb. Res. 97(5), 327-333 (2000).

20. Hashimoto M, Watanabe S, Oiwa $\mathrm{K}$ et al. Enhanced thrombolysis induced by argatroban or activated protein $\mathrm{C}$ in the presence or absence of staphylokinase, measured in an in vivo animal model using mesenteric arterioles. Haemostasis 31(2), 80-89 (2001).

21. Hashimoto M, Onobayashi Y, Oiwa K, Giddings JC, Yamamoto J. Enhanced endogenous thrombolysis induced by a specific factor Xa inhibitor, DX-9065a, evaluated in a rat arterial thrombolysis model in vivo. Thromb. Res. 106(2), 165-168 (2002).

22. Hashimoto M, Yamashita T, Oiwa K, Watanabe S, Giddings JC, Yamamoto J. Enhancement of endogenous plasminogen activator-induced thrombolysis by argatroban and APC and its control by TAFI, measured in an arterial thrombolysis model in vivo using rat mesenteric arterioles. Thromb. Haemost. 87(1), 110-113 (2002).

- He-Ne laser-induced thrombosis test can assess thrombolysis (in vivo).

23. Hashimoto M, Oiwa K, Matsuo O et al. Suppression of argatroban-induced endogenous thrombolysis by PKSI-527, and antibodies to TPA and UPA, evaluated in a rat arterial thrombolysis model. Thromb. Haemost. 89(5), 820-825 (2003).

24. Kearney K, Tomlinson D, Smith K et al. Hypofibrinolysis in diabetes: a therapeutic target for the reduction of cardiovascular risk. Cardiovasc. Diabetol. 16(1), 34 (2017).

25. Wada T, Gando S, Ono Y et al. Disseminated intravascular coagulation with the fibrinolytic phenotype predicts the outcome of patients with out-of-hospital cardiac arrest. Thromb. J. 14, 43 (2016).

26. Poon MC, Di Minno G, d'Oiron R et al. New insights into the treatment of glanzmann thrombasthenia. Transfus. Med. Rev. 30(2), 92-99 (2016).

27. Yau JW, Teoh H, Verma S. Endothelial cell control of thrombosis. BMC Cardiovasc. Disord. 15, 130 (2015).

28. Harrison P. Platelet function analysis. Blood Rev. 19, 111-123 (2005).

29. Paniccia R, Priora R, Liotta AA, Abbate R. Platelet function tests: a comparative review. Vasc. Health. Risk Manag. 11, 133-148 (2015).

- $\quad$ First review citing Global Thrombosis Test (GTT).

30. Gorog DA. Prognostic value of plasma fibrinolysis activation markers in cardiovascular disease. J. Am. Coll. Cardiol. 55(24), 2701-2709 (2010).

31. Gorog DA, Jeong YH. Platelet function tests: why they fail to guide personalized antithrombotic medication. J. Am. Heart Assoc. 4, e002094 (2015).

- Describes platelet function measurement.

32. Okafor ON, Gorog DA. Endogenous fibrinolysis: an important mediator of thrombus formation and cardiovascular risk. J. Am. Coll. Cardiol. 65(16), 1683-1699 (2015).

- Describes the importance of endogenous fibrinolysis measurement.

33. Baumgartner HR. Effects of anticoagulation on the interaction of human platelets with subendothelium in flowing blood. Schweiz. Med. Wochenscher. 106, 1367-1368 (1976). 
34. Sakariassen KS, Aarts PAMM, de Groot PG, Houdijk WPM, Sixma JJ. A perfusion chamber developed to investigate platelet interaction in flowing blood with human vessel wall cells, their extracellular matrix and purified components. J. Lab. Clin. Med. 102, 522-535 (1983).

- Describes the parallel-plate perfusion chamber.

35. Barstad RM, Roald HE, Cui W, Turitto VT, Sakariassen KS. A perfusion chamber developed to investigate thrombus formation and shear profiles in flowing native blood at the apex of well-defined stenoses. Arterioscler. Thromb. 14, 1984-1991 (1994).

- Describes the parallel-plate perfusion chambers with various stenoses.

36. Kirchhofer D, Tschopp TB, Hadváry P, Baumgartner HR. Endothelial cells stimulated with tumor necrosis factor-alpha express varying amounts of tissue factor resulting in inhomogenous fibrin deposition in a native blood flow system. Effects of thrombin inhibitors. J. Clin. Invest. 93(5), 2073-2083 (1994).

37. Sakariassen KS. Thrombus formation on apex of arterial stenoses: the need for a fluid high shear diagnosis device. Future Cardiol. 3(2), 193-201 (2007).

38. Sakariassen KS, Turitto VT, Baumgartner HR. Recollections of the development of flow devices for studying mechanisms of hemostasis and thrombosis in flowing whole blood. J. Thromb. Haemost. 2(10), 1681-1690 (2004).

- Describes frontier research, shear-induced thrombosis, using native blood.

39. Sakariassen KS, Orning L, Turitto VT. The impact of blood shear rate on arterial thrombus formation. Future Sci. OA 1(4), FSO30 (2015).

- Describes the impacts of shear rate and shear stress on arterial thrombus formation.

40. Ratnatunga CP, Edmondson SF, Rees GM et al. High-dose aspirin inhibits shear-induced platelet reaction involving thrombin generation. Circulation 85(3), 1077-1082 (1992).

- This is the first POC instrument.

41. Ikarugi H, Taka T, Nakajima $\mathrm{S}$ et al. Norepinephrine, but not epinephrine, enhances platelet reactivity and coagulation after exercise in humans. J. Appl. Physiol. 86(1), 133-138 (1985).

- Describes relation between platelet function and catecholamineby the first type POC, Haemostatometer using native blood.

42. Gorog DA, Kovacs IB. Thrombotic status analyser. Measurement of platelet-rich thrombus formation and lysis in native blood. Thromb. Haemost. 73(3), 514-520 (1995).

- Describes the second type POC, Thrombotic Status Analyzer.

43. Nakajima S, Noguchi T, Taka T et al. A global platelet test of thrombosis and thrombolysis detects a prothrombotic state in some patients with non-insulin dependent diabetes and in some patients with stroke. Platelets 11(8), 459-466 (2000).

44. Yamamoto J, Yamashita T, Ikarugi H et al. Görög Thrombosis Test: a global in-vitro test of platelet function and thrombolysis. Blood Coagul. Fibrinolysis 14(1), 31-39 (2003).

- The first article on GTT.

45. Yamamoto J, Inoue N, Otsui K et al. Global Thrombosis Test (GTT) can detect major determinants of haemostasis including platelet reactivity, endogenous fibrinolytic and thrombin generating potential. Thromb. Res. 133(5), 919-926 (2014).

- The first article on the upgraded GTT.

46. Ikarugi H, Yamashita T, Aoki R et al. Impaired spontaneous thrombolytic activity in elderly and in habitual smokers, as measured by a new global thrombosis test. Blood Coagul. Fibrinolysis 14(8), 781-784 (2003).

- Describes the difference between the endogenous fibrinolytic activity by age and smoking using GTT.

47. Ikarugi H, Taka T, Nakajima $S$ et al. Significantly reduced spontaneous thrombolytic activity in older men: a possible explanation for the gender differences in risk of acute coronary syndromes. Thromb. Res. 116(2), 127-131 (2005).

48. Suehiro A, Wakabayashi I, Yamashita T et al. Attenuation of spontaneous thrombolytic activity measured by the global thrombosis test in male habitual smokers. J. Thromb. Thrombolysis 37(4), 414-418 (2014).

49. Suehiro A, Wakabayashi I, Uchida K et al. Impaired spontaneous thrombolytic activity measured by global thrombosis test in males with metabolic syndrome. Thromb. Res. 129(4), 499-501 (2012).

- Describes endogenous fibrinolytic activity in patients with metabolic syndrome by GTT.

50. Taomoto K, Ohnishi H, Kuga Y et al. Platelet function and spontaneous thrombolytic activity of patients with cerebral infarction assessed by the global thrombosis test. Pathophysiol. Haemost. Thromb. 37(1), 43-48 (2010).

- Describes platelet function and endogenous fibrinolytic activity in patients with stroke by GTT.

51. Otsui K, Gorog DA, Yamamoto J et al. Global Thrombosis Test - a possible monitoring system for the effects and safety of dabigatran. Thromb. J. 13, 39 (2015).

52. Otsui K, Yamamoto J, Inoue N. Overwork accelerates thrombotic reaction implications for the pathogenesis of karoshi. J. Thromb. Thrombolysis doi:10.1007/s11239-017-1605-y (2017) (Epub ahead of print).

53. Niespialowska-Steuden M, Markides V, Farag M et al. Catheter ablation for AF improves global thrombotic profile and enhances fibrinolysis. J. Thromb. Thrombolysis 44(4), 413-426 (2017). 
54. Christopoulos C, Farag M, Sullivan K, Wellsted D, Gorog DA. Impaired thrombolytic status predicts adverse cardiac events in patients undergoing primary percutaneous coronary intervention. Thromb. Haemost. 117(3), 457-470 (2017).

55. Farag $\mathrm{M}$, Niespialowska-Steuden $\mathrm{M}$, Okafor $\mathrm{O}$ et al. Relative effects of different non-vitamin $\mathrm{K}$ antagonist oral anticoagulants on global thrombotic status in atrial fibrillation. Platelets 27(7), 687-693 (2016).

56. Rosser G, Tricoci P, Morrow D et al. PAR-1 antagonist vorapaxar favorably improves global thrombotic status in patients with coronary disease. J. Thromb. Thrombolysis 38(4), 423-429 (2014).

57. Saraf S, Christopoulos C, Salha IB, Stott DJ, Gorog DA. Impaired endogenous thrombolysis in acute coronary syndrome patients predicts cardiovascular death and nonfatal myocardial infarction. J. Am. Coll. Cardiol. 55(19), 2107-2115 (2010).

58. Gorog DA, Yamamoto J, Saraf S et al. First direct comparison of platelet reactivity and thrombolytic status between Japanese and western volunteers: possible relationship to the 'Japanese paradox'. Int. J. Cardiol. 152(1), $43-48$ (2011).

59. The Dutch Dietary guidelines. www.nature.com/ejcn/journal/v70/n8/pdf/ejcn201652a.pdf

60. The British Dietary guidelines. www.nutrition.org.uk/healthyliving/healthydiet/eatwell.html

61. The United States Dietary guidelines. https://health.gov/dietaryguidelines/2015/guidelines/chapter-1/a-closer-look-inside-healthy-eating-patterns/\#table-1--1

62. The Dutch Physical activity guidelines. www.euro.who.int/__data/assets/pdf_file/0011/288119/NETHERLANDS-Physical-Activity-Factsheet.pdf?ua=1

63. The British Physical activity guidelines. www.nutrition.org.uk/healthyliving/an-active-lifestyle/how-much-physical-activity-do-i-need.html?limit=1\&start=4

64. The United States Physical activity guidelines. https://health.gov/paguidelines/guidelines/summary.aspx

65. Health Japan 12 (the second team). www.mhlw.go.jp/seisakunitsuite/bunya/kenkou_iryou/kenkou/kenkounippon21/en/kenkounippon21/mokuhyou05.html

66. How to be more active? www.nibiohn.go.jp/eiken/info/pdf/active2013-e.pdf

67. Satija A, Bhupathiraju SN, Spiegelman D et al. Healthful and unhealthful plant-based diets and the risk of coronary heart disease in U.S. adults. J. Am. Coll. Cardiol. 70(4), 411-422 (2017).

68. Yamamoto J, Taka T, Yamada K et al. Tomatoes have natural anti-thrombotic effects. Br. J. Nutr. 90(6), 1031-1038 (2003).

- Describes that the antithrombotic activity of tomatoes depends on varieties by shear-induced thrombosis/thrombolysis test using native blood.

69. Yamada K, Naemura A, Sawashita $\mathrm{N}$ et al. An onion variety has natural antithrombotic effect as assessed by thrombosis/thrombolysis models in rodents. Thromb. Res. 114(3), 213-220 (2004).

70. Naemura A, Mitani T, Ijiri Y et al. Anti-thrombotic effect of strawberries. Blood Coagul. Fibrinolysis 16(7), 501-509 (2005).

71. Yamamoto J, Naemura A, Ijiri Y et al. The antithrombotic effects of carrot filtrates in rats and mice. Blood Coagul. Fibrinolysis 19(8), 785-792 (2008).

72. Hyodo K, Horii I, Nishino M et al. The antithrombotic effects of onion filtrates in rats and mice. Health 3(6), 319-325 (2011).

73. Ijiri Y, Yamamoto J, Wako T et al. Experimental antithrombotic effect of garlic varieties measured by a global in vitro test of platelet reactivity and spontaneous thrombolytic activity. Int. J. Drug Dev. Res. 8(2), 11-17 (2016).

74. Yamamoto J, Ijiri Y, Tamura Y et al. Reevaluation of antithrombotic fruits and vegetables: great variation between varieties. Drug Discov. Ther. 10(3), 129-140 (2016).

- Describes that antithrombotic activity depends on varieties in each species.

75. Naemura A, Ohira H, Ikeda M et al. An experimentally antithrombotic strawberry variety is also effective in humans. Pathophysiol. Haemost. Thromb. 35(5), 398-404 (2006).

- Describes that antithrombotic activity experimentally proven in vitro can show the same activity in vivo in humans after acute intake.

76. Ijiri Y, Ishii H, Yamamoto J. Diet of fruits and vegetables with experimental antithrombotic effect may be beneficial to humans in the prevention of arterial thrombotic diseases. Int. J. Drug Dev. Res. 8(3), 12-16 (2016).

- Describes that antithrombotic activity acutely proven in vitro can show antithrombotic activity in vivo in humans after long-term intake.

77. Miyachi M. Measures of physical activity and exercise for health promotion by the Ministry of Health, Labour and Welfare. J. Phys. Fitness. Sports Med. 1(3), 467-472 (2012).

78. Miyachi M, Tripettr J, Kawakami R, Murakami H. '+ 10 min of physical activity per day': Japan is looking for efficient but feasible recommendations for its population. J. Nutr. Sci. Vitaminol. 61, S7-S9 (2015).

79. Bassett DR Jr, Wyatt HR, Thompson H et al. Pedometer-measured physical activity and health behaviors in U.S. adults. Med. Sci. Sports Exerc. 42(10), 1819-1825 (2010). 
80. Billinger SA, Arena R, Bernhardt J et al. Physical activity and exercise recommendations for stroke survivors: a statement for healthcare professionals from the American Heart Association/American Stroke Association. Stroke 45(8), 2532-2553 (2014).

81. Haskell WL, Lee IM, Pate RR et al. Physical activity and public health: updated recommendation for adults from the American College of Sports Medicine and the American Heart Association. Circulation 116(9), 1081-1093 (2007).

82. Lavie CJ, Thomas RJ, Squires RW et al. Exercise training and cardiac rehabilitation in primary and secondary prevention of coronary heart disease. Mayo. Clin. Proc. 84, 373-383 (2009).

83. Shiroma EJ, Lee IM. Physical activity and cardiovascular health lessons learned from epidemiological studies across age, gender, and race/ethnicity. Circulation 122, 743-752 (2010).

84. Pollock ML, Franklin BA, Balady GJ et al. Resistance exercise in individuals with and without cardiovascular disease: benefits, rationale, safety, and prescription: an advisory from the Committee on exercise, rehabilitation, and prevention, council on clinical cardiology, American Heart Association. Circulation 101, 828-833 (2000).

85. Albert CM, Mittleman MA, Chae CU et al. Triggering of sudden death from cardiac causes by vigorous exertion. N. Engl. J. Med. 343 , 1355-1361 (2000).

86. Maron BJ. The paradox of exercise. N. Engl. J. Med. 343, 1409-1411 (2000).

87. Ikarugi H, Yamamoto J. The exercise paradox may be solved by measuring the overall thrombotic state using native blood. Drug Discov. Ther. 11(1), 15-19 (2017).

- Describes the exercise paradox can be avoided by assessing thrombotic status of individuals. 
